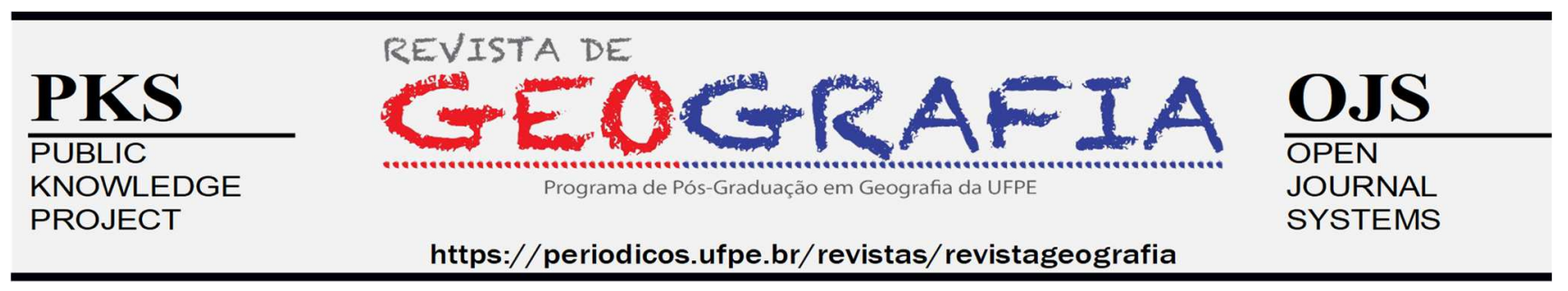

\title{
FRONTEIRA: VIOLAÇÕES QUE PERPASSAM A LINHA CONVENCIONAL
}

\author{
Luzia de Kassia Rocha de Souza ${ }^{1}$
}

${ }^{1}$ Mestra em geografia, especialista em educação e direitos humanos, assistente social. Universidade Federal da Grande Dourados UFGD. E-mail: luziakass@gmail.com, Orcid: http://orcid.org/0000-0002-6061-0893.

Artigo recebido em 11/06/2020 e aceito em 21/02/2021

\begin{abstract}
RESUMO
São as implicações por vezes ofuscadas das relações sociais nas fronteiras, que este artigo pretende explanar. O objetivo é aludir elementos para conhecer e problematizar a interpretação de fronteira, compreendendo a sua conformação além de um dado geográfico, ou técnico, considerando-a, um fato permeado por violações da dignidade humana. Serão apresentadas concepções de fronteira e de direitos humanos, e também dois exemplos de violações etnocêntricas que ocorrem pelas circunstâncias das fronteiras: a primeira no contexto da luta pela sua travessia e a outra é a imposição de humilhações pelo fato de habitar ou estudar na fronteira em cidades gêmeas.
\end{abstract}

Palavras-chave: Fronteira. Outro. Direitos Humanos. Criança e adolescente. Violações

\section{BORDER: VIOLATIONS THAT PASS THE CONVENCIONAL LINE OVER}

\begin{abstract}
Are the implications that many times ofuscated from the social relations on the borders, wich this article intends to explain. The purpose is to allude elements to know and problematize the interpretation of border, including your conformation besides a geographical or technical data, considering it, a fact permeated by violations of human dignity. Will be presented conceptions of border and human rights, also two examples of ethnocentric violations wich happen by circunstances of borders: The first on the context of fight for crossing and the other is the imposition of derogatory treatment by living or studying on the border of twin cities.
\end{abstract}

Keywords: border. Other. Human rights. Child and teenager. Violations

\section{FRONTIÈRE: VIOLATIONS DE LA LIGNE CONVENTIONNELLE}

\section{RÉSUMÉ}

Ils sont les implications souvent obscurcie des relations sociales dans les frontières, que cet article a l'intention d'expliquer. L'objectif est de mentionner des éléments pour connaître et à problematize l'interprétation de frontière, comprenant sa démission en plus un géographique meurt, ou le technicien, la considérant, un fait pénétré par les violations de la dignité humaine. Les conceptions de frontière seront présentées et de droits de l'homme et aussi deux exemples des violations ethnocentriques qui arrivent pour les circonstances des frontières: le premier dans le contexte du combat pour son croisement et l'autre est l'imposition d'humiliations pour le fait d'habiter ou étudier dans la frontière dans des villes jumelées.

Mots-clés: Fronteière. Autre. Droits de l'homme. Enfants et adolescente. Violations 


\section{INTRODUÇÃO}

Parece acabado e inofensivo utilizar fronteira para expressar uma linha que determina os confins de um Estado, cidade, país, continente ou a demarcação de terras dos povos originários. Numa primeira aproximação, as fronteiras podem ser lembradas fisicamente como altos e longos muros, cercas, emaranhados de fios ou trechos longos e temidos; matas, mar e desertos, embora não seja sempre esse o caso. Nas cartografias dos mapas, por exemplo, parecem apenas riscos vermelhos estáticos, que nada mais fazem além de separar. O fato importante é que ao atravessar esse limite (a fronteira) entra-se no território ${ }^{1}$ do outro $^{2}$, onde há o contraste de valores e concepções sobre humanidade. O limite e o encontro entre lugares e culturas são marcados historicamente, entre outros fatos, por graves conflitos.

Este artigo, divide-se em dois eixos. No primeiro serão apresentadas concepções de fronteira e direitos humanos. E no segundo, estudos de casos, a saber, dois exemplos de violações etnocêntricas que ocorrem pelas circunstâncias das fronteiras. O primeiro no limite entre México e Estados Unidos no contexto da luta pela sua travessia; o segundo refere-se a fronteira entre Brasil e Paraguai, trata da imposição de humilhações pelo fato de habitar ou estudar na fronteira em cidades gêmeas, no domínio de discriminações de cunho xenófobo apoiados em valores culturais que aviltam a dignidade humana e resulta na limitação do acesso ao direito humano à educação e, logo, correspondem a reprodução das relações sociais no contexto globalizado na perspectiva sócio-espacial ${ }^{3}$.

\section{ABORDAGENS CONCEITUAIS SOBRE FRONTEIRA E DIREITOS HUMANOS}

A reflexão sobre o sentido de fronteira se faz necessária, dentre muitos aspectos, pela invisibilidade do desrespeito à dignidade humana em suas circunstâncias, como a negação de todos os bens essenciais à manutenção da vida, no caso das travessias, até o acesso ao direito humano à educação na ocorrência de discriminações. (RAFFESTAIN 2005, p. 9) assevera que "a ausência de reflexão a respeito do significado de fronteira ratifica a falta do regramento nos diversos aspectos do pensamento e da ação". Tais discussões se encontram, por vezes, localizadas no campo distorcido de veiculação da grande mídia, no entanto, neste artigo, as violações apresentadas e as concepções que

\footnotetext{
${ }^{1}$ Território é fundamentalmente um "espaço definido e delimitado por e a partir de relações de poder.” SOUZA, Marcelo Lopes de Souza. Conceitos fundamentais da pesquisa sócio-espacial. Rio de janeiro. Bertrand Brasil, 2013.

${ }^{2}$ Nós, corresponde aos europeus e os outros somos nós, os povos do mundo periférico. TZVETAN, Todorov. Nós e os outros. A reflexão francesa sobre a diversidade humana. Zahar - Rio de Janeiro, 1993.

3 Sócio-espacial: estudo das relações sociais na conformação dos espaços, considerando as variadas, distintas e complexas dimensões: econômica, política e social, como processos vivos. SOUZA, Marcelo Lopes de Souza. Conceitos fundamentais da pesquisa sócio-espacial. Rio de janeiro. Bertrand Brasil, 2013.
} 
serão problematizadas posteriormente se pautam em trabalhos acadêmicos, aduzidos por meio de pesquisas.

Nesse sentido, para uma breve demarcação temporal sobre limite territorial (ZUSMAN 2017, p. 51) esclarece que "entre finales del siglo XIX y principios del XX, en el proceso de definición de los Estados nacionales latinoamericanos, los diplomáticos de los países firmaban tratados orientados a estabelecer los límites internacionales" nesse contexto, para (ZUSMAN 2017, p. 50) "la técnica há sido una de las grandes protagonistas de la modernidade ${ }^{4}$. Vale ressaltar, de acordo com (SANTOS 2006, p. 29) que, "as técnicas são um conjunto de meios instrumentais e sociais com os quais o homem realiza sua vida, produz e, ao mesmo tempo, cria o espaço" entretanto, de modo contraditório, a técnica fora utilizada como instrumento de emancipação e também de dominação. Em consonância com (ZUSMAN 2017, p. 51) "la selección y control de la movilidad de la población adquiere preeminencia por sobre la demarcación territorial. Asimismo, sobre las fronteras definidas en el período anterior, se definen jerarquias.” Demarcação territorial e fronteiras atendem, portanto, a instalação de um projeto de poder e dominação com ressalvas acentuadas de organização hierárquica.

Desse modo, a concepção de fronteira e também a de humanidade na civilização ocidental se dirigem ao marco político europeu, uma vez que "a história do sistema-mundo moderno tem sido, em grande parte, a história da expansão dos povos e dos Estados europeus pelo resto do mundo" (WALLERSTEIN 2007, p. 29). Sendo assim, para a concepção de humanidade no contexto das fronteiras, o documento de pactuação entre as nações de maior relevância internacional, a Declaração Universal dos Direitos Humanos (DUDH), preconiza em seu artigo VI que "todo ser humano tem o direito de ser, em todos os lugares, reconhecido como pessoa perante a lei”. Vale ressaltar que ser reconhecido como pessoa, receber a titulação de ser humano, prevê não somente a saciação das necessidades básicas essenciais à manutenção da vida, mas isso associado ao tratamento digno em qualquer circunstância ou lugar no mundo.

Flores (2009) ${ }^{5}$ afirma, contudo, que o universalismo dos poderosos sempre foi parcial e distorcido, um universalismo que [ele] chama de 'universalismo europeu' por ter sido criado por líderes pan-europeus na tentativa de defender os interesses do estrato dominante do sistema-mundo moderno. Ou seja, a garantia da dignidade humana, em determinados contextos, fica condicionada aos interesses dos choques de civilizações, permanecendo superior à cultura mais civilizada. Sendo

\footnotetext{
${ }^{4}$ A modernidade é uma máquina geradora de alteridades que, em nome da razão e do humanismo, exclui de seu imaginário a hibridez, a multiplicidade, a ambiguidade e a contingência das formas de vida concretas. CASTRO-GÓMEZ, Santiago. Ciências sociais, violência epistêmica e o problema da 'invenção do outro'. CLACSO, Consejo Latinoamericano de Ciencias Sociales. 2005, p. 87.

${ }^{5}$ Cf. HERRERA-FLORES, Joaquin. A (re)invenção dos direitos humanos. Florianópolis (SC): Fundação Boiteux; IDHID, 2009.
} 
assim, os interesses da interpretação de fronteira e de sua função também se submetem à reafirmação dos valores eurocêntricos, dando lugar ao branco e civilizado (nas situações de disputa ou de estabelecimento de padrões) como superior em relação ao outro em qualquer lugar e circunstância em que haja conflito.

Nesse sentido (BAUMAN 2005, p. 41) menciona que, "guiada pelas leis humanas, a humanidade seguiu em frente se arrastando, enquanto era fustigada, pressionada e atormentada pelas forças da irracionalidade, do preconceito e da superstição”. (RAFFESTIN 2005, p. 11), por sua vez, reitera a presença dessas forças na conformação das fronteiras. Logo, atesta que "a fronteira nasce da diferença. Eu chamaria de forma saliente a toda forma vivida que se separa nitidamente do fundo contínuo sobre o qual se destaca". De modo consequente, a fronteira expressa a materialização dos limites subjetivos da humanidade em termos de rejeição, indiferença e desrespeito ao outro; o que ela mostra, a fronteira, é o espelho das práticas humanas no cotidiano, e se estabelece dialeticamente nas relações humanas.

No âmbito dos estudos sobre fronteiras, seus precursores no Brasil são sociólogos e antropólogos. Eles centraram pesquisas nas relações do contato interétnico e sobre diversidade na perspectiva de sociedades distintas, como Ribeiro (1995) ${ }^{6}$ e Martins (1997), este mais especificamente nos estudos relativos ao campesinato. Conforme (MARTINS 1997, p. 11)

\begin{abstract}
A fronteira é, sobretudo, no que se refere aos diferentes grupos dos chamados civilizados que se situam "do lado de cá", um cenário de intolerância, ambição e morte. É, também, lugar de elaboração de uma residual concepção de esperança, atravessada pelo milenarismo da espera no advento do tempo novo, um tempo de redenção, justiça, alegria e fartura.
\end{abstract}

A esperança em atravessar a fronteira, por vezes, significa se salvar da pobreza, guerra, perseguição política, escassez de bens e serviços necessários à manutenção da vida. Isto porque as pessoas que se submetem aos perigos e humilhações ao lutar para atravessar uma fronteira (em especial em zona fronteiriça entre países marcados por desníveis de civilização) emigrando de um país, deixando seus hábitos para viver outra cultura, já estavam em situação de risco e violação de direitos humanos básicos. A fuga, portanto, emerge como alternativa de sobrevivência, uma vez que o país mais civilizado é, ao mesmo tempo, o explorador e a esperança de condições para uma vida melhor.

Em diferentes partes do mundo existem pessoas cruzando fronteiras em busca da sobrevivência. Na América Latina, por exemplo, há, entre outras, a situação dos venezuelanos, que, fugindo da crise vivida naquele país, buscam no Brasil uma oportunidade de se refugiarem. Em que

\footnotetext{
${ }^{6}$ Cf. RIBEIRO, Darcy. O Povo Brasileiro: a formação e o sentido de Brasil. São Paulo: Companhia das Letras, 1995.
} 
pese, o Brasil não poder $^{7}$ negar (deliberadamente) o refúgio, ao chegarem em terras brasileiras, esses imigrantes ficam submetidos a diversas violações de direitos humanos, como trabalho análogo à escravidão, discriminação salarial em função da origem, mendicância de crianças e adolescentes em semáforos, relatos de abuso sexual de mulheres contratadas para trabalhar como domésticas e prostituição ${ }^{8}$.

\title{
OBJETOS QUE “FALAM” SOBRE O LIMITE ENTRE MÉXICO E ESTADOS UNIDOS
}

Nas mais variadas expressões de violações dos direitos humanos, não mensuráveis em importância, existem situações ainda mais agravadas do que aquela enfrentada pelos venezuelanos na saga pelo cruzamento da fronteira. Há degradação da dignidade humana em níveis extremos, ao ponto de as pessoas serem identificadas e valorizadas como lixo. Detalhes neste sentido podem ser observados em análise de (SUNDBERG 2017, p. 10), que assevera:

\begin{abstract}
Mi atención se centra en la frontera entre Estados Unidos y México, y especificamente, en los encuentros cercanos entre los ciudadanos estadounidenses, la evidencia material de los migrantes indocumentados y sus movimientos fronterizos (no autorizados). Los materiales encontrados abarcan tanto documentos de identidad, recuerdos personales así como otros elementos necesarios para sobrevivir como botellas de agua, paquetes de comida, medicación, sapatos, ropas y mochilas. (SUNDBERG, 2017, p. 10)
\end{abstract}

As evidências materiais do empenho em cruzar a fronteira sem documentos se configuram em objetos e denunciam a existência de um número expressivo de pessoas que se movimentam na tentativa de atravessar determinada fronteira. De acordo com Sundberg (2017) tais objetos têm recebido atenção dos meios de comunicação nacionais e locais e também de artistas e defensores do meio ambiente. Em se tratando da concepção do cidadão estadunidense e da pauta dos meios de comunicação, a preocupação maior está na sujeira provocada pelos objetos deixados à deriva ao longo do deserto, que implicam, entre outras questões, em prejuízo aos negócios relacionados ao turismo.

Segundo (SUNDBERG 2017, p. 11), "para los inmigrantes indocumentados, el cruce del límite entre México y Estados Unidos es hoy un viaje que amenaza la propia vida y requiere resistencia física". Isto porque,

Antes los migrantes indocumentados entraban a Estados Unidos a través de las ciudades populosas de la frontera, hoy tienen que recorrer largas distancias através de terrenos hostiles, escassamente habitado. Este cambio geográfico en el movimiento fronterizo data de 1994. (SUNDBERG 2017, p. 11)

7 Cf. Decreto $\mathrm{n}^{\circ}$ 50.215/1961. Convenção relativa ao estatuto dos refugiados. Disponível em: http://www.planalto.gov.br/ccivil_03/decreto/1950-1969/D50215.htm acessado em: 20/02/2021.

8 Cf. https://agenciabrasil.ebc.com.br/direitos-humanos/noticia/2018-02/procuradora-denuncia-violacoes-de-direitoshumanos-de-venezuelanos acessado em: 20/02/2021. 
O resultado é a impossibilidade de calcular o número de mortos. A morte como ponto final denuncia o flagelo da pessoa emigrante. Não se trata de morrer a curto prazo, ou rapidamente; é a negação da dignidade humana em uma de suas representações extremas. Tiram-se aos poucos, durante a saga, todos os bens necessários à sobrevivência. De acordo com (SUNDBERG 2017, p. 25), “a los fines de ir de un lugar a otro, ellos necesitan mochilas, zapatos, ropas, ellos necesitan todo, todas los elementos para sobrevivir. Y gastan mucho dinero en estas cosas... y no querían dejarlos, pero tuvieron que hacerlo, para su propia sobrevivencia, no tuvieron otra alternativa". Trata-se de objetos que remetem às necessidades essenciais. Não é muito complexo precisar a falta que um básico par de sapatos, por exemplo, pode fazer na travessia do deserto. Aproximando um pouco mais (SUNDBERG 2017, p. 10) informa que:

Los cambios en el reforzamiento de la frontera han derivado em el aumento en el número de muertes de migrantes; la mayoria de las muertes ocurren en el Desierto de Sonora; entre 1990-2005, la Oficina del Médico Forense de Tucson, Arizona se ocupó de 927 cuerpos recuperados (Rubio-Goldsmith et al., 2006).

Ressalte-se que o reconhecimento universal da dignidade - é inerente a todo ser humano e assegurado pela garantia de direitos, sem exceção e discriminação por motivo de raça, cor, sexo, língua, religião, opinião política ou de outra natureza, origem nacional ou social, situação econômica, nascimento ou qualquer outra situação - conta com documentos e acordos internacionais, como o Pacto Internacional Sobre os Direitos Civis e Políticos ${ }^{9}$ e o Pacto Internacional sobre Direitos Econômicos, Sociais e Culturais ${ }^{10}$. Os pactos mencionados preveem as três dimensões de direitos individuais, sociais e coletivos - garantem ao ser humano o acesso aos bens necessários à vida, como liberdade, água, alimento, saúde, educação, trabalho decente, vida cultural, enfím as condições básicas para sobrevivência e tratamento digno.

Cada objeto, contudo, denuncia uma violação. Interconectadas, essas violações corroboram para a negação do direito humano à vida. Destaca-se a presença de crianças (e a violação da sua dignidade) na luta pela travessia da fronteira

En el techo del ómnibus se encuentra una mochila de Barbie todavía con agua en su pequeno termo rosa. "Supongo que ella [la mochila] perteneció quizás a una niña pequeña. Ella no quería dejarla, ella le costó a su mamá... le costó su dinero. Estas personas provienen de pueblos donde no pueden permitirse una mierda, ellos no quieren dejarlo ahí". (SUNDBERG 2017 , p. 25)

\footnotetext{
${ }^{9}$ Cf. Decreto $\mathrm{n}^{\circ}$ 592/1992. Atos Internacionais. Pacto Internacional sobre Direitos Civis e Políticos. Disponível em: http://www.planalto.gov.br/ccivil 03/decreto/1990-1994/d0592.htm acessado em: 17/02/2021.

${ }^{10}$ Cf. Decreto no 591/1992. Atos Internacionais. Pacto Internacional sobre Direitos Econômicos, Sociais e Culturais. Disponível em: http://www.planalto.gov.br/ccivil 03/decreto/1990-1994/d0591.htm acessado em: 17/02/2021.
} 
Por muitos motivos a criança pode ter deixado para trás aquela mochilinha rosa contra a sua vontade. Um deles é não ter conseguido mais carregá-la, por cansaço ou por inanição. Para (SUNDBERG 2017, p. 25) há muitas razões, podemos apenas especular. "Quizás el coyote estaba allí, esperando y dijo 'ok, deje todas las cosas', y seguro la niña pequeña decía 'no, no, yo quiero llevarla'. 'No, no puedes'. 'Yo quiero llevarla, yo quiero llevarla,' y la madre decía, 'podemos llevarla, sabés, pero ella nos costó mucho dinero'. 'No"'. A perseguição e também a indiferença quanto ao valor dos objetos (as necessidades básicas que eles suprem, como, por exemplo, a garrafa para água), é a mesma em relação à criança.

A Convenção Internacional Sobre os Direitos da Criança (CDC) ${ }^{11}$ acordou e decreta direitos que estabelecem a maneira como devem ser tratadas as crianças e adolescentes para que seja assegurado o respeito à sua dignidade humana no âmbito internacional. A CDC conta com 195 Estados Partes; recentemente a Organização das Nações Unidas (ONU) saudou a ratificação do Sudão do Sul. Cabe ressaltar a não retificação por parte dos Estados Unidos: assim que finalizar o processo de ratificação da Somália já iniciado - esperando apenas ser formalizado - os Estados Unidos são o único país que ainda não ratificou o tratado histórico ${ }^{12}$. A negligência em não se tornar signatário é compatível com a concepção dos estadunidenses sobre os objetos encontrados. Conforme (SUNDBERG 2017, p. 19)

En sus intervenciones políticas, los ciudadanos estadounidenses usan los objetos dejados por los migrantes indocumentados para expresar su visión sobre las políticas migratorias y sobre los migrantes. A pesar de que ellos constituyeran parte integral de la vida diaria y de que fueran necesarios para la sobrevivencia de los migrantes, los manifestantes producían estos objetos como desechos, colocándolos en bolsas de basura.

Por este ângulo, é como se os objetos tivessem sido deixados em lugares impróprios. Seriam as pessoas envolvidas em travessia ilegal de fronteira as deixadoras de lixo por toda parte do deserto. Este posicionamento atesta uma indiferença absoluta quanto ao sofrimento que os objetos refletem. No entanto, esta concepção não está isolada. Além da opinião política, manifestantes com pressupostos ambientalistas se posicionam e, segundo (SUNDBERG 2017, p. 17), reiteram:

De acuerdo al artículo de Sierra Vista Herald, los manifestantes aparentemente acusaron a Kolbe de "no hacer nada para evitar la degradación del ambiente por los inmigrantes ilegales" (Hess, 2003). Sin embargo, para estos manifestantes, los migrantes parecen implicar necesariamente basura, sin importarles por qué ellos ingresan a Estados Unidos o de dónde ellos provienen (del desierto o del patio trasero). La mención al despliegue de ingenieros sanitarios para limpiar "los residuos" "antiestéticos" y "malolientes" refuerza la asociación

11 Cf. decreto $\mathrm{n}^{\text {o }}$ 99.710/1990. Convenção sobre os direitos da criança. Disponível em: http://www.planalto.gov.br/ccivil_03/decreto/1990-1994/d99710.htm acessado: 17/02/2021.

12 Cf. https://nacoesunidas.org/onu-com-adesao-do-sudao-do-sul-apenas-eua-nao-ratificaram-convencao-sobre-osdireitos-das-criancas/ acessado em: 17/02/2021. 
entre los trabajadores migrantes y los desechos, y los produce como personas no higiénicas, indisciplinadas, con comportamientos corporales inadecuados.

A urgência em limpar os resíduos deixados pelos emigrantes ilegais na fronteira sem maiores questionamentos quanto às suas vidas, e ainda a dignidade das pessoas condicionadas ou comparadas às suas mochilas de lixo, causam indignação por tamanha indiferença e crueldade. Parece-nos distante, porém, é arquétipo da reprodução das relações sociais e expressa a linha que separa a ordem do caos, e também, inevitavelmente os valores, opiniões, concepções e posicionamento da humanidade perante uns aos outros. Nesse sentido, (BAUMAN 2005, p. 33) pondera que:

\footnotetext{
Nenhum objeto é "refugo" por suas qualidades intrínsecas, e nenhum pode tornar refugo mediante a sua lógica interna. É recebendo o papel de refugo nos projetos humanos que os objetos materiais, sejam eles humanos ou inumanos, adquirem todas as qualidades misteriosas, aterrorizantes, assustadoras e repulsivas.
}

Todas as qualidades repulsivas impostas ao outro, aquele que tenta atravessar ilegalmente a fronteira, também pode amedrontar (assim como amedronta o seu lixo) pela sua pobreza e necessidade. A violência, por exemplo, pode lhe estar à flor da pele, já que há coragem para enfrentar qualquer desafio e turbulência para atravessar a fronteira. Para (BAUMAN 2005, p. 33):

Os coletores de lixo são os heróis não decantados da modernidade. Dia após dia, eles reavivam a linha de fronteira entre normalidade e patologia, saúde e doença, desejável e repulsivo, aceito e rejeitado, o comme il fout e o comme il ne faut pas, o dentro e o fora do universo humano. Essa fronteira precisa da constante diligência e vigilância porque não é absolutamente uma "fronteira natural": não há montanhas altíssimas, oceanos sem fundo ou gargantas intransponíveis separando o dentro e o fora. (BAUMAN 2005, p. 33)

A zona cinzenta e contraditória que separa o produto útil do lixo é a mesma ambivalência que define os humanos dignos dos outros. A maneira como cada pessoa se percebe perante as demais corrobora na construção da primeira fronteira separando cada uma. Vale ressaltar a dimensão sofisticada que a materialização das fronteiras tem recebido para o seu reforçamento no âmbito globalizado, como, por exemplo, o muro entre o México e os Estados Unidos, que, segundo (ZUSMAN 2017, p. 54) conta com "dispositivos como cámaras, sensores y rastreadores a lo largo de 1200 kilómetros. Estos dispositivos, en conexión con la policía fronteriza, permitirían detectar movimientos en un perímetro de siete quilômetros". O empenho e o investimento financeiro para o reforçamento da demarcação territorial por meio da fronteira são imensuráveis se comparados à articulação de políticas voltadas à qualidade de vida na Terra.

A prioridade em tecnologia para a segurança em defesa e demarcação do poder se sobressai em detrimento da consolidação dos acordos internacionais no domínio da dignidade humana. (ZUSMAN 2017, p. 54) informa que “en setiembre de 2006, el Congreso de Estados Unidos votó el Secure Fence Act que autorizo a dar continuidad a la construcción del muro establecido entre México 
y Estados Unidos durante el gobierno de Bill Clinton en 1994". Nesse seguimento, é importante lembrar que outros países têm absorvido o empenho em tecnologias para o controle fronteiriço.

Tal es el caso de Brasil que, siguiendo las directrices del Plan Estratégico de Fronteras establecido en el año 2011, propuso el desarrollo de un Sistema Integrado de Vigilancia de la Áreas de Frontera (SISFRON) por medio del uso de tecnologías de monitoreo y sensores remotos. El sistema previó la utilización de radares de corto y largo alcance, equipamiento de visión nocturna, torres de visión y transmisión de señales, cámaras ópticas y termales o producción deimágenes por satélites. (ZUSMAN 2017, p. 54)

Materializadas em muros ou não, as zonas de fronteira recebem considerável investimento financeiro e em pesquisas, portanto as inovações neste âmbito, desenvolvem tecnologias muito eficientes e assim possibilitam a criação de mecanismos capazes de captarem minunciosamente a presença humana para o monitoramento intensivo e controle das fronteiras.

\section{INTERCULTURALIDADE E PROCESSO EDUCATIVO NA FRONTEIRA ENTRE BRASIL}

\section{E PARAGUAI}

Existem limítrofes entre países em que não há cerca, deserto ou mar, para demarcar os confins de ambos. Nessas circunstancias a fronteira não deixa de existir, ela é instalada nas relações sociais, e evidenciada pelas atitudes discriminatórias no cotidiano. Nessa perspectiva vale aludir:

Ponta Porã, localizada no Mato Grosso do Sul, Brasil, e Pedro Juan Cabalerro, capital do departamento de Amambay, no Paraguai, são cidades localizadas numa fronteira seca, separadas unicamente por uma zona neutra, uma faixa de poucos metros que as comissões limítrofes reservam nas fronteiras urbanas secas e que pertence aos Estados vizinhos. Entre as duas cidades não existem barreiras que dificultem ou impeçam a comunicação entre seus habitantes, o que favorece o contato cotidiano entre as populações de ambos os países. (NUNES 2015, p. 144)

O sentido da fronteira, nesse caso, sinaliza os confins e a separação para demarcar território e os aspectos referentes à soberania, mas não há, desse modo, limites materializados para atravessar. Portanto (NUNES 2015, p. 144) destaca, "a fronteira ultrapassa o sentido comum de limite, de divisão ou de delimitação, carregando uma carga contraditória, pois se separa também evidencia identidades indicando espaço de tangência e de potenciais identificações (sociais, culturais, econômicas e políticas)" nesse contexto, é possível, e, por vezes, a melhor ou única alternativa para as pessoas, morar em um país e ter acesso aos direitos sociais, como educação e saúde, no outro país. De acordo com (NUNES 2015, p.141):

Devido às condições econômicas e desiguais entre as duas nações, muitas famílias paraguaias registram seus filhos no Brasil para que eles tenham acesso à educação formal brasileira. Sendo assim, esses alunos de cultura paraguaia, falando castelhano e guarani, acabam sofrendo com a rotina escolar que se pauta no contexto cultural da sociedade brasileira. 
O acesso ao direito humano à educação se interconecta com as demais necessidades humanas essenciais, e é imprescindível. A limitação desse direito interfere na capacidade de exigir e exercer direitos civis, políticos, econômicos, sociais e culturais. Não havendo planejamento que priorize a comunicação e os demais aspectos que a fronteira emergente da língua representa, o acesso à educação fica comprometido. Entretanto, segundo a Convenção Internacional dos Direitos da Criança (art. 28 .3), da qual o Brasil é signatário:

Os Estados Partes promoverão e estimularão a cooperação internacional em questões relativas à educação, especialmente visando a contribuir para a eliminação da ignorância e do analfabetismo no mundo e facilitar o acesso aos conhecimentos científicos e técnicos e aos métodos modernos de ensino. A esse respeito, será dada atenção especial às necessidades dos países em desenvolvimento.

A consolidação do direito humano à educação, todavia, conta com um entrave maior: um ambiente hostil. Isto é, a escola por um viés perpassado por discriminação, instigado por valores de cunho eurocêntrico sedimentado na cultura brasileira, que se reproduz na escola, vindo do contexto globalizado, e da escola, novamente para sociedade em detrimento dos povos originários. O nós, portanto, não corresponde mais exatamente àquele de origem europeia, como superior ao outro, os nativos, os povos ancestrais, originários, mas, o nós, agora, somos os brasileiros, submersos em valores europeus, que temos nos paraguaios o sujeito outro. De acordo com (NUNES 2015, p. 142)

\begin{abstract}
Nessa direção, fronteira passa a ser o território de invenção do outro, onde o indivíduo procura se reconhecer frente àquilo que é imposto, ou aceito, como o único, e àquilo que vivencia como alteridade e diferenças. Essa alteridade decorre do fato de que o outro possui uma temporalidade, por conseguinte uma história, diferente da nossa. Tal desencontro de temporalidade instaura a consciência de que não existe só uma linha, ritmo e evolução histórica, aquela que entendemos como nossa. Eis um dos grandes entraves no processo de aceitação do outro, ou seja, entender e respeitar que numa mesma espacialidade podem ocorrer e conviver diferentes temporalidades e histórias.
\end{abstract}

Aceitar o processo histórico de cada pessoa implica na aceitação de si próprio. $\mathrm{O}$ respeito à autonomia e dignidade do outro refletem a concepção que cada pessoa tem sobre si mesma na sua autonomia e dignidade. A discriminação no domínio da escola é resultado disso e, ao mesmo tempo, corrobora para o etnocentrismo, a saber, em consonância com (CARVALHO 1997, p. 181) “o etnocentrismo consiste em privilegiar um universo de representações propondo-o como modelo e reduzindo à insignificância os demais universos e culturas diferentes" determinado modelo interfere nas relações sociais no âmbito global.

Nesse sentido, o viés hostil da escola aqui ressaltado não pretende pormenorizar o problema do eurocentrismo ou identificar culpados, mas, sim, refletir sobre as violações de direitos humanos que implicam na limitação do acesso à educação e atestam os valores da sociedade. Serão 
apresentadas, portanto, narrativas docentes aludidas em pesquisa realizada em escolas públicas no município de Ponta Porã, em Mato Grosso do Sul. As escolas definidas são as com maior número de estudantes oriundos do Paraguai.

Todos os trechos das narrativas destacados a partir deste momento estão presentes no trabalho de Terenciani (2011). Esta autora utilizou nomes fictícios para garantir o anonimato dos professores entrevistados, pois, em seu entendimento, o elemento da não identificação possibilitou que estes se manifestassem de forma mais aberta e à vontade durante as entrevistas. Ademais, acreditamos que as identificações não são necessárias para o trabalho, haja vista que buscamos compreender, mediante a pesquisa qualitativa e por amostragem, a prática docente de professores de Geografia da cidade de Ponta Porã, sem que para isso tenhamos de identificar os sujeitos da pesquisa. (NUNES 2015, p. 145 apud TERENCIANI 2001, p. 20)

As narrativas de professores revelam os meandros na conformação dos valores distorcidos que favorecem a rejeição aos povos originários. "No ano passado (2009), no $9^{\circ}$ ano, os alunos só falavam o guarani. Tive que intervir... os professores não conseguem entender o que está sendo dito. Fui lá e falei pra eles não falarem mais o guarani, porque se estão aqui (na escola) são brasileiros e têm que se comportar como brasileiros..." esta é a resposta de um entre os dois professores entrevistados sobre a presença de alunos de origem paraguaia nas escolas brasileiras. De acordo com Nunes apud Terenciani, o segundo entrevistado pontuou:

A partir do momento em que eles estão em escolas brasileiras, eles se dizem brasileiros, são brasileiros, documentadamente brasileiros, e é assim que nós os vemos. Não tem distinção entre o brasileiro e o paraguaio, porque aqui na escola os dois são brasileiros. Agora... continuam agindo como se fossem paraguaios... falam a língua deles dentro de sala de aula e isto é uma dificuldade para nós. (NUNES 2015, p. 146 apud TERENCIANI 2011, p. 152)

Culpar a criança por ser quem ela é, impor-lhes a condição de desajustada, é um aspecto cultural e histórico no comportamento da sociedade brasileira, em especial em relação aos pobres. É comum, por exemplo, posicionamentos desconectados de precedentes históricos, em que há culpabilização das pessoas pelas violações que estão submetidas. O fato é que culpar é mais fácil do que elaborar propostas inclusivas. Pondera-se, neste sentido, que desde a promulgação da DUDH a humanidade "progrediu" na proposição de acordos e pactos internacionais que permitem a elaboração de propostas para favorecer a interculturalidade ${ }^{13}$. De acordo com (BOBBIO 2004, p. 31)

Além de processos de conversão em direito positivo, de generalização e de internacionalização, manifestou-se nestes últimos anos uma nova linha de tendência, que se pode chamar de especificação; ela consiste na passagem gradual, porém cada vez mais

\footnotetext{
${ }^{13}$ Ser ciudadano intercultural quiere decir, en primer lugar, ser capaz de elegir la propia cultura, es decir, elegir practicar las creencias, los usos y costumbres heredados del ethos al que pertenezco, o en su defecto, decidir apartarme de ellos por consideraciones valorativas que considero más plausibles. Ser ciudadano intercultural es por ello ejercer el derecho a construirse una identidad cultural propia, y no limitarse a reproducir en uno mismo ni la identidad heredada ni la identidad que la sociedad mayor nos fuerza a adoptar por todos los médios. TUBINO, Fidel. Del interculturalismo funcional al interculturalismo crítico. Red Internacional de Estudios Interculturales - 2002, p. 07.
} 
acentuada, para uma ulterior determinação dos sujeitos titulares de direitos. Ocorreu, com relação aos sujeitos, o que desde o início ocorrera com relação à ideia abstrata de liberdade, que se foi progressivamente determinando em liberdades singulares e concretas de consciência, de opinião, de imprensa, de reunião e de associação.

A afirmação da liberdade e da dignidade humana, além de estabelecida em proposição universal, está também especificada, seja em relação ao gênero ou às várias fases da vida, seja na infância, adolescência, de qualquer origem. Enfim, o acesso às condições básicas que afirmam a dignidade do ser humano, determina a ideia de igualdade e equidade, ou seja, a garantia do acesso à educação, de maneira igual, mesmo que seja para pessoas de origens diferentes. Considerando mais um possível entrave, vale destacar, no entanto, que:

Outra pesquisadora dos processos educativos em escolas de fronteira, Fedatto aponta que a escola de fronteira não é diferenciada, entre outros motivos, porque os professores não recebem formação para tal atuação, ou seja, desde a graduação estes não estão preparados para trabalharem com tal realidade mesmo que esta esteja à sua volta. Muitos são sabem como fazer a relação entre a teoria e a prática, o que culmina na homogeneização do ensino. (NUNES 2015, p. 144 apud FEDATTO 2005, p. 495)

Nesse sentido, evidencia-se o fato de alguns professores apresentarem concepções distintas em relação aos alunos rotulados como diferentes:

Olha, não existe projeto que tente trabalhar com esta diversidade, e isso parte também da direção da escola, que também não faz nada para se adaptar a isso, tá... Como ele (o aluno) tem toda essa cultura paraguaia, acaba atrapalhando as aulas, porque ele está em contato com o que acontece no Paraguai e não no Brasil, né? (NUNES 2015, p. 148 apud TERENCIANI 2011, p. 152-153)

Metodologia e ações necessárias para construir um currículo inclusivo compõem, desse modo, o quadro de negligência que a concepção das narrativas citadas atestam em relação à aceitação de crianças e adolescentes paraguaios nas escolas brasileiras. Conforme a narrativa de outra professora, quando entrevistada sobre a presença de estudante de origem paraguaia na escola brasileira:

Existe uma resistência muito grande aqui na fronteira. Eu já ouvi professores, colegas meus, dizerem assim: "Ah, eles vêm estudar aqui, eles que têm que se adaptar, não somos nós que temos que se adaptar a eles". Isso é doloroso, né? Então, eles esquecem da dívida que temos para com o Paraguai por conta da Guerra da Tríplice Aliança contra o Paraguai, né? Esquecem de que a hegemonia na fronteira tá nas mãos dos brasileiros, né? Que é uma porção de coisas que acontecem nesse contexto de fronteira e que a criança é que tem que se virar. "Ela é que se vire", se ela não aprende o problema é dela. (NUNES 2015, p. 147 apud TERENCIANI 2011, p. 151)

Reconhecer e valorizar o outro no paraguaio é tão difícil quanto aceitar a ancestralidade indígena e latina para o brasileiro, que se instala, nesta perspectiva, no lugar do nós, os mais civilizados, talvez eurocentricamente mais ajustados. As narrativas oriundas das escolas alertam para a necessidade de que as agendas públicas, as políticas sociais e também os currículos carecem de um novo posicionamento e não mais apenas de leis que contemplem a equidade. "Visibilizar la diversidad 
cultural como valiosa y el reconocimiento de las diferencias como un necesario principio rector de formas de convivencia más justas que no existen aún", aponta (TUBINO 2002, p. 03). Para incluir de fato, não basta estar escrito, é necessário atitude, considerar, reconhecer e permitir a beleza do outro.

É lamentável a eleição de uma só identidade cultural como superior. De maneira generalizada, limita e força a adoção dos hábitos de uma só cultura por todas as pessoas. Trata-se de um empobrecimento imensurável. "La interculturalidad no es un concepto, es una manera de comportarse. No es una categoría teórico, es una propuesta ética" (TUBINO 2002, p. 03) que possibilita a abolição do universo interior. Reconhecer em si a ancestralidade é também se permitir a "novas" experiências e sensibilidades. "Más que una idea es una actitud, una manera de ser necesaria en un mundo paradójicamente cada vez más interconectado tecnológicamente y al mismo tiempo más incomunicado interculturalmente" (TUBINO 2002, p. 03). O pensamento sobre a atitude é também um modo de agir; pensar em propositura intercultural possibilita a eliminação de possíveis fronteiras etnocêntricas na reprodução das relações sociais.

Outras expressões culturais remetem à oportunidade de sair do domínio "asséptico" e limitado da imposição de uma só cultura. Portanto:

\begin{abstract}
A partir das ideias presentes na fala do professor, notamos que existe uma concepção de que a diferença representada pelo aluno de origem paraguaia é vista como um fator negativo na escola. Na opinião do professor, o fato do aluno ter um convívio cotidiano com a língua e costume do Paraguai causa uma "confusão", pois o aluno chega à escola e "mistura tudo". Mas podemos, então, questionar: não seria esse o elemento que proporcionaria o contato com a diversidade e as potencialidades culturais presentes no cotidiano da fronteira? Não seria possível que a escola utilizasse essa especificidade para desenvolver processos de ensinoaprendizagem mais adequados à realidade de seus alunos, ao invés de impor a homogeneização desses processos com base num único referencial de conhecimento e cultura? (NUNES 2015, p. 150).
\end{abstract}

Entender como ensejo precioso, valor e beleza a diversidade cultural ainda pode representar uma opção para cada pessoa. Contudo "un mundo em el que los graves conflictos sociales y políticos que las confrontaciones interculturales producen, empiezan a ocupar un lugar central en la agenda pública de las naciones" (TUBINO 2002, p. 03). Contando com marcos legais, resta, entretanto, prioridade, que pelo exposto, pode estar condicionada às concepções pessoais dos gestores públicos e trabalhadores da educação sobre fronteira, direitos humanos de crianças e adolescentes, interculturalidade e em especial, sobre o acesso ao direito humano a educação.

\title{
CONSIDERAÇÕES FINAIS
}

Este empenho, defere reflexões sobre a interpretação de fronteira e de sua função como materialidade daquela fronteira que se manifesta primeiramente no comportamento de cada pessoa, a 
partir da sua interpretação de si mesma e do mundo, e interfere na concepção sobre dignidade humana e consequentemente na consolidação dos direitos humanos.

Antes de tudo, a fronteira nasce da diferença, e vale lembrar que a diferença que determina o limite entre o nós e o outro na fronteira interior de cada pessoa, não é uma atitude espontânea. Tratase da imposição do processo de expansão dominante, do advento da modernidade como geradora de alteridade e também de democracia. A consolidação dos direitos humanos previsto em constituições democráticas, encontra entraves relativos ao reconhecimento da diferença, os quais fazem com que a concepção de humanidade e a consolidação dos direitos humanos se condicionem às contradições inerentes ao universalismo europeu.

A gravidade das violações de direitos humanos nas circunstancias das fronteiras aqui explanadas, a fronteira simbólica e a materializada, atestam a indiferença às mazelas que aviltam a dignidade humana, inclusive o desprezível trato dispensado às crianças e adolescentes. A negligência dos países e suas respectivas agendas públicas, está evidenciada na imperiosa presença de ciência e tecnologia para reforços ao monitoramento da segurança nas fronteiras, em detrimento de investimento em políticas públicas que alcance factivelmente a consolidação de direitos muito básicos como o acesso à educação.

Determinada segurança, direcionada as zonas fronteiriças dos países - materializada por altíssimo nível de eficiência à captura da presença humana - dispõem de empenho em inteligência e pesquisa suficiente para resultar em excelência nos avanços da tecnologia, este fato associado a perseguição e morte dos emigrantes do percurso até o limite, pode ser considerado o cúmulo da contradição da proposta de universalização dos direitos humanos, perante as privações aos bens essenciais à manutenção da vida (como a água) sofridas pelas pessoas adultas, crianças e adolescentes no contexto da luta pela travessia dessa mesma fronteira, tão bem equipada e protegida.

\section{REFERÊNCIAS}

BAUMAN, Z. Vidas desperdiçadas. Tradução: Carlos Alberto Medeiros. Rio de Janeiro: Zahar, 2005.

BOBBIO, N. A era dos direitos. Nova ed. Rio de Janeiro: Elsevier, 2004.

BRASIL. Declaração Universal dos Direitos Humanos de 1948. Disponível em: http://www.dhnet.org.br/direitos/deconu/textos/integra.htm acessado em: 07 de janeiro de 2021.

Decreto $n^{0}$ 99.710, de 21 de novembro de 1990. Convenção sobre os Direitos da Criança. Disponível em: http://www.planalto.gov.br/ccivil_03/decreto/1990-1994/d99710.htm acessado em: 17 de fevereiro de 2021. 
CARVALHO, J. C. de P. Etnocentrismo: inconsciente, imaginário e preconceito no universo das organizações educativas. Interface (Botucatu) vol.1 no.1 Botucatu Aug. 1997. Disponível em: http://www.scielo.br/pdf/icse/v1n1/14.pdf acessado em: 17 de fevereiro de 2021.

MARTINS, J. de S. Fronteira: a degradação do outro nos confins do humano. São Paulo: Hucitec, 1997.

NUNES, F. G. Narrativas docentes da/na fronteira: identidade, alteridade e diferença na prática de ensino e na formação de professores de Geografia. In: Portugal, Jussara F.; CHAIGAR, Vânia M. Educação geográfica: memórias, história de vida e narrativas docentes. Salvador: EDUFBA, 2015.

RAFFESTAIN, C. A ordem e a desordem ou os paradoxos da fronteira. In.: Oliveira, Tito C. M. de (Org.) Território sem limite - estudos sobre fronteira. Campo Grande (MS): Ed. UFMS, 2005.

SANTOS, M. A Natureza do Espaço: Técnica e Tempo, Razão e Emoção. 4. ed. São Paulo: Editora da Universidade de São Paulo, 2006.

SUNDBERG, J. Fronteras íntimas y geopolítica cotidiana en la zona fronteriza entre Estados Unidos-México. Revista de Geografía Norte Grande, 2017.

TUBINO, F. Del interculturalismo funcional al interculturalismo crítico. Red Internacional de Estudios Interculturales, 2002.

WALLERSTEIN, I. M. O universalismo europeu: a retórica do poder. São Paulo: Boitempo, 2007.

ZUSMAN, P. La técnica y la definición de las fronteras. Revista de Geografia Norte Grande, Santiago, n. $\quad 66, \quad 2017 . \quad$ Disponível em: https://scielo.conicyt.cl/scielo.php?script=sci arttext\&pid=S0718-34022017000100004 acessado em: 18 de fevereiro de 2021. 